\title{
DIREITO PÚBLICO SUBJETIVO E POLÍTICAS EDUCACIONAIS
}

\author{
Clarice Seixas Duarte
}

\begin{abstract}
Resumo: O presente artigo aborda o regime jurídico aplicável ao ensino fundamental, buscando analisar se a figura jurídica do direito público subjetivo presta-se à exigibilidade judicial de políticas públicas educacionais, tendo em vista, especialmente, a necessidade de adaptação do conceito ao contexto de uma Constituição que adota o modelo do Estado Social de Direito.

Palavras-chave: direitos sociais; direito público subjetivo; políticas públicas educacionais.
\end{abstract}

\begin{abstract}
The present article discusses the juridical system applied to the middle school. It analyzes the juridical role of the subjective public right to check if it is pertinent to the judicial demands of the educational public politics. It considers especially the need of adaptation of the concept into the context of a Constitution that adopts the State Social of Right.

Key words: social rights; subjective public right; educational public politics.
\end{abstract}

$\mathrm{O}$ presente artigo tem como objetivo examinar se a figura jurídica do direito público subjetivo, prevista no art. 208, § $1^{\circ}$ da Constituição Federal Brasileira de 1988, para disciplinar o acesso ao ensino obrigatório e gratuito, presta-se à exigibilidade judicial de políticas públicas educacionais. Para tanto, serão analisadas as condições de adaptabilidade do instituto, desenvolvido na Alemanha no final do século XIX, ao contexto de uma Constituição do Estado Social de Direito, notadamente no que se refere à ampliação de sua titularidade e de seu objeto, sempre à luz dos princípios que informam nosso ordenamento jurídico.

Entretanto, em que consiste, afinal, o direito público subjetivo? O jurista alemão Georg Jellinek, cuja obra, publicada em 1892, é um marco para a temática, definiu esta figura jurídica como sendo "o poder da vontade humana que, protegido e reconhecido pelo ordenamento jurídico, tem por objeto um bem ou interesse" (Jellinek, 1910:10). Trata-se de uma capacidade reconhecida ao indivíduo em decorrência de sua posição especial como membro da comunidade, que se materializa no poder de colocar em movimento normas jurídicas no interesse individual. Em outras palavras, o direito público subjetivo confere ao indivíduo a possibilidade de transformar a norma geral e abstrata contida num determinado ordenamento jurídico em algo que possua como próprio. A maneira de fazê-lo é acionando as normas jurídicas (direito objetivo) e transformando-as em seu direito (direito subjetivo). ${ }^{1}$

$\mathrm{O}$ interessante é notar que o direito público subjetivo configura-se como um instrumento jurídico de controle da atuação do poder estatal, pois permite ao seu titular constranger judicialmente o Estado a executar o que deve. De fato, a partir do desenvolvimento deste conceito, passou-se a reconhecer situações jurídicas em que o Poder Público tem o dever de dar, fazer ou não fazer algo em benefício de um particular. Como todo direito cujo objeto é uma prestação de outrem, ele supõe um comportamento ativo ou omissivo por parte do devedor.

Na realidade, a grande inovação desta figura, na época de seu surgimento na Alemanha no final do século XIX, foi o reconhecimento de um poder de exigência (pretensão) do particular em face dos Poderes Públicos, tendo como objeto a prestação devida. ${ }^{2}$ Como pressuposto para a aceitação deste poder conferido ao indivíduo, está a idéia de que entre o Estado e seus membros existe uma relação jurídica e, conseqüentemente, os conflitos dela resultan- 
tes podem ser resolvidos judicialmente (Estrada, 1997), ao contrário, por exemplo, do que ocorria no Estado Absolutista, em que os súditos eram vistos apenas como sujeitos de deveres e obrigações. Ocorre que a jurisdicização das relações instauradas com o Estado implica, necessariamente, a limitação de seu poder. Aliás, foi o processo de luta pela limitação do poder absoluto que resultou em uma série de modificações nas organizações das instituições modernas, notadamente no que se refere à evolução do conceito de personalidade individual, elemento fundamental para a compreensão da teoria de Jellinek sobre os direitos públicos subjetivos.

$\mathrm{Na}$ visão deste autor, a personalidade é uma categoria própria do direito público, formada pelo conjunto de capacidades jurídicas reconhecidas e concedidas ao indivíduo pelo ordenamento estatal e por meio da qual o homem é elevado à condição de sujeito de direito, passando a fazer parte da tutela jurídica. É da personalidade jurídica do indivíduo que deriva a possibilidade de provocar o Estado no interesse individual, colocando em movimento normas do ordenamento jurídico (Jellinek, 1910:62-63; 92-93). Note-se que o acionamento do ordenamento é feito em nome da perseguição de vantagens individuais, justamente porque o interesse individual é reconhecido como merecedor de uma proteção jurídica especial. Na prática, criase um mecanismo de defesa contra abusos do poder estatal e proteção da liberdade individual, ideais fortemente identificados com os valores do pensamento jurídico liberal.

Tradicionalmente, no modelo do Estado Liberal clássico, a exigibilidade individual de direitos civis e políticos sempre esteve calcada no reconhecimento de uma posição jurídica que confere aos seus titulares a possibilidade de barrarem qualquer intervenção estatal indevida em sua esfera própria de liberdade. ${ }^{3}$ De acordo com esta concepção, o que se pretende é uma omissão (conduta negativa) dos Poderes Públicos: não agir de forma arbitrária, ou seja, desrespeitando os parâmetros legais previamente estabelecidos. Entretanto, a busca por um patamar mínimo de igualdade, não apenas jurídica mas também material e efetiva - grande bandeira dos direitos sociais $^{4}$-, exige uma posição ativa do Estado no que se refere à proteção de direitos, pois o que se pretende é criar, por parte dos Poderes Públicos, condições concretas de vida digna.

Assim, no contexto das Constituições do Estado Social, que incorporaram em seu catálogo um extenso rol de direitos sociais, o grande desafio é conter os abusos causados pela inércia estatal no cumprimento do dever de realizar prestações positivas. Estas prestações nada mais são do que as políticas públicas objeto dos direitos sociais reconhecidos constitucionalmente. Em outras palavras, o controle da atuação do Estado não mais está adstrito à exigibilidade de uma conduta negativa e ao respeito aos parâmetros legalmente estabelecidos (não invadir a esfera de liberdade do indivíduo, senão expressamente autorizado em lei), mas deve estar voltado ao cumprimento dos objetivos e programas de ação governamentais constitucionalmente delineados (como os direitos sociais à educação, à saúde, ao trabalho, dentre outros previstos no artigo $6^{\circ}$ da Constituição Federal de 1988). O importante é notar que, nestes casos, o que se busca não é mais uma abstenção, mas a realização de direitos por meio da implementação de sistemas públicos adequados de saúde, educação, assistência social, etc.

A implementação dos programas constitucionalmente delineados, ou dos sistemas públicos necessários à efetivação dos direitos sociais, se faz por meio de um conjunto de atos que podem adquirir as mais diferentes formas de expressão jurídica. De fato, para dar concretude a uma política pública, são tomadas medidas que, embora unidas por objetivos comuns, têm natureza jurídica distintas, tais como: leis ordinárias ou complementares; medidas provisórias; emendas constitucionais; decretos; planos; atos administrativos; regulamentos; etc. (Bucci, 2002).

Os instrumentos jurídicos citados constituem apenas parte de um processo complexo, que envolve diferentes etapas até a concretização de uma política pública, da formação e planejamento à execução e avaliação (Bucci, 2002). O processo inicia-se pela escolha das prioridades e dos meios adequados para atingir os fins estabelecidos, além da determinação dos caminhos a serem adotados. Um outro elemento essencial da política pública diz respeito à previsão de financiamento, pois a destinação de recursos é indispensável à contratação de pessoal, oferta de serviços, etc. Por fim, deve haver uma fase de avaliação dos resultados da política adotada, o que inclui o controle e a fiscalização de sua implementação pela sociedade civil, pelos Tribunais de Contas, Conselhos Gestores de Políticas Públicas e, até mesmo, pelo Judiciário.

Do ponto de vista jurídico, dada a complexidade deste conjunto de medidas, o grande desafio tem sido o de estabelecer mecanismos para garantir a exigibilidade e o controle judicial do seu cumprimento, em caso de ausência ou insuficiência das políticas adotadas. Será que a figura clássica do direito público subjetivo seria o meio adequado para tanto? 
Ora, reconhecer ao indivíduo (deixemos, por ora, o problema dos grupos vulneráveis, alvos prioritários dos direitos sociais) a possibilidade de interferir nas decisões sobre alocação de recursos, realização de programas sociais, definição de prioridades de ação governamental, sobretudo pela via judicial, é uma hipótese vista com grande resistência por boa parte da doutrina e da Jurisprudência. Entende-se que o Judiciário acabaria tendo que julgar questões cuja apreciação são da esfera do juízo de oportunidade e conveniência da Administração Pública. Na prática, o risco da chamada "politização" do Judiciário acaba funcionando como uma grande barreira à efetivação dos direitos sociais.

Entretanto, e quando a Constituição reconhece, expressamente, um direito social como um direito público subjetivo, como o fez com o ensino obrigatório e gratuito (cf. art. 208, $\left.\S 1^{\circ} \mathrm{da} \mathrm{CF} / 88\right)$ ? Quais as conseqüências práticas daí advindas? Ela reconhece o direito a uma pretensão individual (uma vaga na escola), ou à realização de políticas públicas? Esta figura presta-se a esses objetivos indistintamente?

$\mathrm{O}$ reconhecimento expresso do direito ao ensino obrigatório e gratuito como direito público subjetivo autoriza a possibilidade de, constatada a ocorrência de uma lesão, o mesmo ser exigido contra o Poder Público de imediato e individualmente. Quanto a este aspecto, parece não haver muita polêmica. Ocorre que, como estamos diante de um direito social, o seu objeto não é, simplesmente, uma prestação individualizada, mas sim a realização de políticas públicas, sendo que sua titularidade se estende aos grupos vulneráveis. É isso o que será demonstrado em seguida.

Em primeiro lugar, vale lembrar que o direito à educação não se reduz ao direito do indivíduo de cursar o ensino fundamental para alcançar melhores oportunidades de emprego e contribuir para o desenvolvimento econômico da nação. Deve ter como escopo o oferecimento de condições para o desenvolvimento pleno de inúmeras capacidades individuais, jamais se limitando às exigências do mercado de trabalho, pois o ser humano é fonte inesgotável de crescimento e expansão no plano intelectual, físico, espiritual, moral, criativo e social. ${ }^{5} \mathrm{O}$ sistema educacional deve proporcionar oportunidades de desenvolvimento nestas diferentes dimensões, preocupando-se em fomentar valores como o respeito aos direitos humanos e a tolerância, além da participação social na vida pública, sempre em condições de liberdade e dignidade. Assim, no Estado Social, a proteção do direito individual faz parte do bem comum.
Ora, não se pode esquecer que o direito público subjetivo visa resguardar interesses individuais quando os mesmos coincidem com o interesse público. Isso significa que o reconhecimento de que o indivíduo pode fazer funcionar a máquina estatal em seu interesse não se choca com o bem comum; ao contrário, faz parte dele. $\mathrm{O}$ reconhecimento de pretensões aos indivíduos pela lei vem reforçar a proteção de sua liberdade e não transformá-los em direitos privados.

O importante é perceber que a implantação de um sistema público adequado de educação interessa não apenas aos beneficiários diretos do serviço (alunos), mas à coletividade, já que a educação escolar constitui um meio de inserir as novas gerações no patrimônio cultural acumulado pela humanidade, dando-lhe continuidade. Quando um indivíduo exerce seu direito ao ensino obrigatório de forma isolada e não coletiva, ele está acionando uma norma geral e abstrata em seu interesse próprio. Contudo, vale destacar que, para o indivíduo fazer funcionar a máquina estatal em seu interesse, é preciso que, por trás do interesse particular, também o interesse público seja protegido (afinal, trata-se de um direito público). Aliás, este aspecto assume função de destaque no quadro de um Estado Social, pois o objeto da proteção recai sobre um direito social e este aspecto não pode ser desprezado.

O grande problema, hoje, não é mais a fundamentação e o reconhecimento da exigibilidade individual do direito à educação, mas sim a interpretação do atual sentido de uma figura jurídica, que, embora tenha surgido para proteger valores marcadamente individualistas (resguardar o cidadão contra interferências abusivas do Estado na sua esfera de liberdade), está inserida num novo contexto. Uma compreensão adequada do direito público subjetivo deve levar em conta os parâmetros que informam a atual Constituição brasileira, notadamente o modelo de Estado por ela adotado, que pressupõe a adoção de uma postura intervencionista na área social. De fato, as novas tarefas impostas aos Poderes Públicos no Estado Social de Direito não se limitam à produção de leis ou normas gerais, mas abrangem a elaboração e implementação de políticas públicas, que se tornam os grandes eixos orientadores da atividade estatal (Comparato, 1998).

É evidente que se as condições de efetivação dos direitos sociais dependem de ações estatais concretas, sem as quais o programa social neles contido não se realiza, isso significa que a sua plena satisfação extrapola o nível da satisfação individual do direito (a determinação judicial da abertura de uma vaga em uma escola pública, por 
exemplo). Na realidade, constitui um dos fundamentos do Estado de Direito Social a possibilidade de participação de todos nos bens da coletividade e uma melhor distribuição desses bens. Se essa participação for negada, pois o Poder Público não organiza sistemas adequados para atender à demanda dos grupos mais despidos de poder, por exemplo, deve-se buscar proteção jurídica para corrigir esta situação indesejada. A figura do direito público subjetivo, quando utilizada para proteger um bem que é ao mesmo tempo individual e social, deve se prestar à exigibilidade do caráter coletivo de tais direitos, ou seja, à exigibilidade de políticas públicas.

No Brasil, especialmente a partir da Constituição Federal de 1988, com a adoção dos princípios do Estado Social e Democrático de Direito, houve uma transformação profunda no cenário jurídico. A previsão de veiculação de conflitos de interesses meta-individuais por meio de ações judiciais - de que são exemplo a ação civil pública, o mandado de injunção, o mandado de segurança coletivo e a ação popular - fez com que essa categoria assumisse novas dimensões. De fato, quando se trata de interesses coletivos ou difusos, é possível afirmar que a ação transformou-se em um canal de participação social na gestão da coisa pública, ou seja, em um instrumento de participação política, o que constitui uma forma de concretizar a democracia participativa consagrada em nosso sistema jurídico.

Contudo, deve-ser frisar que a ação judicial é apenas um canal de exigibilidade do direito subjetivo, e não o seu fundamento. Na realidade, no contexto de um Estado Social, o fundamento para a exigência de cumprimento de uma prestação positiva por parte da administração encontra-se nas leis e políticas públicas constitucionalmente delineadas, que formam a base para a ação concreta dos Poderes Públicos. O desrespeito a estes parâmetros é que enseja uma reação por parte dos cidadãos, sendo a legitimidade de agir a conseqüência processual para remediar esta situação irregular.

Aqui vale a pena explorar uma distinção importante no âmbito da Teoria Geral do Direito, notadamente aquela que se faz entre direitos e garantias: "os direitos representam só por si certos bens, as garantias destinam-se a assegurar a fruição desses bens" (Miranda, 1998:88). O direito público subjetivo, em si, não é uma garantia stricto sensu, embora constitua um instrumento jurídico que veio reforçar o sistema geral de proteção do ensino fundamental como direito social. $\mathrm{Na}$ acepção larga do conceito de garantia, pode-se incluir, no caso da educação, a conside- ração de certos princípios, como o da obrigatoriedade do ensino (entendida como a imposição de um dever ao Estado) e o da sua gratuidade em estabelecimentos oficiais, além da vinculação constitucional de receitas. Todo esse conjunto deve ser interpretado de forma a assegurar a fruição do direito ao ensino fundamental.

Desde o regime anterior, o art. 176 da Emenda Constitucional de 1969 já estabelecia, de forma explícita, a educação como um dever do Estado. Já a vinculação de recursos não constava da Emenda Constitucional de 1969, mas foi re-introduzida em nosso sistema jurídico, em dezembro de 1983, por meio da Emenda Calmon, regulamentada somente em $1985 .{ }^{6}$ Com relação à gratuidade universal do então chamado ensino primário oficial, este princípio já estava presente na Emenda Constitucional de 1967, que manteve, neste particular, o disposto na Constituição de 1946. A gratuidade é um corolário da obrigatoriedade do ensino imposta aos Poderes Públicos.

O que se está pretendendo demonstrar é que alguns dos dispositivos previstos em nossa Constituição atual - como, por exemplo, o art. 205, caput da CF/88 "a educação, direito de todos e dever do Estado (...)" e o art. 208, I "será efetivada mediante a garantia de ensino fundamental, obrigatório e gratuito (...)" são análogos aos previstos na Carta de 1969. Tais dispositivos, independentemente da previsão expressa da figura do direito público subjetivo, eram suficientes para derivar pretensões individuais em face do Estado no campo educacional.

Daí decorre, então, que a Constituição contém um instrumento inútil? Não, pois no contexto de um Estado Social de Direito a figura do direito público subjetivo, quando aplicada a um direito social, deve ser interpretada de forma ampliada em relação ao momento de seu surgimento, sob a égide do Estado Liberal, a fim de assegurar a exigibilidade coletiva e não apenas individual, do bem jurídico protegido. O seu objeto também deve ser alargado, para incluir as políticas públicas. Esta perspectiva, por si só, já diferencia a proteção atual do direito ao ensino fundamental em relação àquela do regime anterior, em que os parâmetros do modelo de Estado Social não estavam previstos.

$\mathrm{Na}$ realidade, o fato de a Constituição atual ter enunciado de forma expressa o direito público subjetivo como regime específico do direito ao ensino fundamental conferiu aos indivíduos, irrecusavelmente, uma pretensão e uma ação para exigirem seus direitos, o que, no caso de outros direitos sociais, vem suscitando maiores objeções, pois o seu objeto primário é a realização de políticas públicas. 
A função de se prever de forma expressa na Constituição que um determinado direito é público subjetivo é afastar, definitivamente, interpretações minimalistas de que direitos sociais não podem ser acionáveis em juízo, nem gerar pretensões individuais. Trata-se de uma figura que vem reforçar o regime já existente, além de constituir uma baliza para a melhor compreensão dos direitos sociais, sob o prisma do seu potencial de efetividade.

Na leitura de Luis Roberto Barroso (1993:106-7), “é bem de ver, no entanto, que o constituinte preferiu não sujeitar-se a riscos de interpretação em matéria à qual dedicou especial atenção: o ensino fundamental. Desse modo, interpretando a si mesmo, fez incluir no $\S 1^{\circ}$ do art. 208 a declaração de que 'o acesso ao ensino obrigatório e gratuito é direito público subjetivo'. O dispositivo, todavia, não deve induzir ao equívoco de uma leitura restritiva: todas as outras situações jurídicas constitucionais que sejam redutíveis ao esquema direito individual-dever do Estado configuram, da mesma sorte, direitos públicos subjetivos".

É interessante notar que, de acordo com a interpretação supracitada, a explicitação do direito público subjetivo não veio conferir um novo regime - em termos qualitativos - ao ensino fundamental em relação aos demais direitos sociais, embora tenha o efeito notável de conferir, de imediato, a todos, uma pretensão individual, dispensando-lhes de terem que provar, como condição de uma ação desta natureza, a não implementação ou insuficiência de uma política pública. No caso de um direito público subjetivo, a pretensão individual é concorrente e não substitutiva em relação à pretensão pública. A previsão expressa de um direito público subjetivo confere, apenas, uma diferença de grau à pretensão. Assim, mesmo para aqueles casos em que o direito público subjetivo não está previsto de forma expressa, o indivíduo tem o direito de exigir uma prestação individual; apenas a pretensão primária é pública (podendo ser exercida pelo Ministério Público, por exemplo) e está voltada, prioritariamente, à exigibilidade de políticas públicas.

Reconhecendo que a derivação de direitos subjetivos diretamente da Constituição, independentemente de previsão expressa, embora absolutamente defensável, não é nada óbvia, acredita-se que a enunciação do ensino fundamental como direito público subjetivo traz conseqüências importantes e que não devem ser subestimadas. ${ }^{7}$ $\mathrm{Na}$ cultura jurídica brasileira, fortemente moldada por valores inerentes ao Estado Liberal de Direito, a utilização de uma categoria consagrada como a do direito público subjetivo para a proteção de um direito social contribui para a superação de certos preconceitos, notadamente aquele relativo ao reconhecimento da exigibilidade coativa e imediata perante o Judiciário desta categoria de direitos.

Note-se que quando o assunto é a efetivação dos direitos sociais pela via do Judiciário, por meio da utilização de remédios constitucionais (garantias processuais), ${ }^{8}$ o que se discute, na realidade, são os limites do jurídico em oposição ao campo reservado à esfera política. Afirmar que a busca pela plena efetivação de direitos sociais implica a necessidade da não omissão do Judiciário em face das demandas que envolvem a implementação de políticas públicas coloca-nos, necessariamente, em conflito com uma das tradições mais arraigadas na cultura jurídica brasileira. Isso porque, para além da questão que envolve a alegada "preservação da separação dos poderes", há, ainda, o ideal de "neutralidade axiológica" nas teorias e de "isenção política” nas práticas jurídicas.

Do que foi exposto neste artigo, pode-se dizer que, se o Executivo, mesmo tendo implementado uma política pública para garantir o ensino fundamental, deixar pessoas privadas de vagas nas escolas por falta de boa execução administrativa, estará sujeito a uma interpelação judicial por via do exercício de uma pretensão individual. Mais do que isso: em que pese o reforço da proteção constitucional conferida ao direito ao ensino fundamental, o regime jurídico geral aplicável aos direitos sociais impõe, por si só, uma nova atitude do Estado, notadamente a promoção de condições concretas de fruição de tais direitos, sempre tendo em vista a realização do princípio da igualdade material (cf. art. $3^{\circ}$, especialmente incisos I e III) e a proteção efetiva da dignidade humana (cf. art. $1^{\circ}$, III), que constituem seus verdadeiros fundamentos.

É importante perceber que o reconhecimento da proteção individual não pode ser negado aos direitos sociais em geral, independentemente de sua previsão expressa como direito público subjetivo. Ainda assim, neste campo, a pretensão pública deve ser prioritária, pois a dimensão social do direito somente se realiza por meio da exigibilidade de políticas públicas, o que envolve interesses que transcendem a esfera do indivíduo singularmente considerado. Esta é a razão pela qual, aliás, insistimos na ampliação do objeto e da titularidade da figura do direito público subjetivo, para abranger as políticas públicas, entendidas como o conjunto de ações que o Poder Público realiza, visando o efetivo exercício da igualdade, base de toda ordem social (Frischeisen, 2000:58). 


\section{NOTAS}

Partes destas idéias foram expostas na tese de doutorado, ver Duarte (2003).

1. "A dicotomia [entre direito objetivo e subjetivo] pretende realçar que o direito é um fenômeno objetivo, que não pertence a ninguém socialmente, que é um dado cultural, composto de normas, instituições, mas que, de outro lado, é também um fenômeno subjetivo, no sentido de que faz, dos sujeitos, titulares de poderes, obrigações, faculdades, estabelecendo entre eles relações. Assim, quando falamos no direito das sucessões significamos algo objetivo, quando mencionamos o direito à sucessão de um herdeiro, mencionamos que algo lhe pertence. Para clarificar, lembramos que o inglês tem duas palavras diferentes para enunciar os dois termos: law (direito objetivo) e right (direito subjetivo)" (Ferraz Júnior, 1994:146, grifos do autor).

2. O reconhecimento de autênticos direitos subjetivos implica, apenas, a pertinência de um bem da vida a alguém. Já a pretensão caracteriza-se pelo poder conferido ao titular de exigir um comportamento positivo ou omissivo por parte do sujeito passivo.

3. Os direitos civis estão, em grande parte, previstos no art. $5^{\circ}$ da Constituição Federal: liberdade de manifestação do pensamento (inciso IV); liberdade de consciência e de crença (inciso VI); direito à intimidade (inciso X); direito de ir e vir (inciso XV); liberdade de associação (inciso XVII), dentre outros. Já os direitos políticos, dentre os quais se destaca o direito de votar e ser votado, estão disciplinados no art. 14 e seguintes do mesmo diploma legal.

4. Os direitos sociais estão, em grande parte, previstos no art. $6^{\circ}$ da Constituição Federal: educação, saúde, trabalho, moradia, lazer, segurança, previdência social, proteção à maternidade e à infância e assistência aos desamparados.

5. Tanto é assim que o artigo 205 da Constituição Federal de 1988 dispõe: "A educação, direito de todos e dever do Estado e da família, será promovida e incentivada com a colaboração da sociedade, visando ao pleno desenvolvimento da pessoa, seu preparo para o exercício da cidadania e sua qualificação para o trabalho" (grifos nossos).

6. A Emenda Calmon foi incorporada à Constituição como o $\S 4^{\circ}$ do art. 176.

7. Uma outra vantagem da previsão expressa do direito público subjetivo ao ensino fundamental decorre mais da natureza deste último do que propriamente da forma de sua proteção. Melhor dizendo: a enunciação de um direito público subjetivo tem muito mais condições de realizar seu potencial se o objeto desse direito e da pretensão estiver bem precisado, o que ocorre no campo da educação. Na realidade, no caso do direito ao ensino fundamental, não há nenhum obstáculo de ordem teórica para que o indivíduo exerça uma pretensão concorrente em relação à pretensão pública (ação civil pública, por exemplo), pois o objeto da pretensão, o bem jurídico protegido, está muito bem delineado em nosso sistema jurídico, que, aliás, conta com uma série de outros mecanismos que apontam na mesma direção: a prioridade absoluta ao ensino fundamental.

8. "A Constituição de 5 de outubro de 1988 foi de todas as Constituições brasileiras aquela que mais procurou inovar tecnicamente em matéria de proteção aos direitos fundamentais. Não o fez porém sem um propósito definido, que tacitamente se infere do conteúdo de seus princípios e fundamentos: a busca em termos definitivos de uma compatibilização do Estado Social com o Estado de Direito mediante a introdução de novas garantias constitucionais, tanto do direito objetivo como do direito subjetivo" (Bonavides, 2000:502). Dentre as "regras de máxima amplitude previstas no propósito de alicerçar essa última modalidade de Estado" [a eficácia do Estado Social assentado sobre as bases do Estado de Direito], o autor destaca: a ação de descumprimento de preceito constitucional, prevista no art. 102 (a argüição de descumprimento de preceito fundamental desta Constituição será apreciada pelo Supremo Tribunal Federal, na forma da lei); a cláusula aberta do art. $5^{\circ}, \S 2^{\circ}$ (os direitos e garantias expressos nesta Constituição não excluem outros decorrentes do regime e dos princípios por ela adotados ou dos tratados internacionais em que a República Federativa do Brasil seja parte); o princípio da aplicabilidade imediata das normas definidoras de direitos e garantias fundamentais (art. $5^{\circ}, \S 1^{\circ}$ ); e a regra que determina a apreciação, pelo Judiciário, de lesão ou ameaça a direito (art. 5 XXXV) (Bonavides, 2000:507).

\section{REFERÊNCIAS BIBLIOGRÁFICAS}

BARROSO, L.R. O direito constitucional e a efetividade de suas normas: limites e possibilidades da Constituição brasileira. 3. ed. Rio de Janeiro: Renovar, 1993.

BONAVIDES, P. Curso de direito constitucional. 10. ed. São Paulo: Malheiros, 2000.

BUCCI, M.P.D. Direito administrativo e politicas públicas. São Paulo: Saraiva, 2002.

COMPARATO, F.K. Ensaio sobre o juízo de constitucionalidade de políticas públicas. Revista de Informação Legislativa, Brasília, Senado Federal, n.138, p.39-48, abr./jun. 1998.

DUARTE, C.S. O direito público subjetivo ao ensino fundamental na Constituição Federal brasileira de 1988. 2003. 328 p. Tese (Doutorado) - Departamento de Filosofia e Teoria Geral do Direito da Universidade de São Paulo, São Paulo, 2003.

ESTRADA, A.J. La teoria de los derechos públicos subjetivos en la obra de Georg Jellinek. Bogotá: Instituto de Estudios Constitucionales Carlos Restrepo Piedrahita, 1997.

FERRAZ Jr., T.S. Introdução ao estudo do Direito: técnica, decisão, dominação. São Paulo: Atlas, 1994.

FRISCHEISEN, L.C.F. Políticas públicas: a responsabilidade do administrador e o Ministério Público. São Paulo: Max Limonad, 2000.

JELLINEK, G. Sistema dei diritti pubblici subbietivi. Milano, 1910.

MIRANDA, J. Manual de direito constitucional. Coimbra, Coimbra Ed., 1998. (Tomo IV - Direitos Fundamentais).

SARLET, I.W. A eficácia dos direitos fundamentais. Porto Alegre: Livraria do Advogado, 1998.

Clarice Seixas Duarte: Vice-presidente do Centro de Direitos Humanos, Professora do programa de Mestrado em Direito Ambiental da Universidade Estadual do Amazonas e Professora convidada do programa de pósgraduação da Universidade Católica de Santos (clasduarte@uol.com.br). 